\section{Michigan Technological 18 8 5 University}

Michigan Technological University Digital Commons @ Michigan Tech
Global Conference of the Youth Environmental Alliance in Higher Education

Dec 9th, 3:29 PM - 3:40 PM

\title{
Session 2B Smart Cities Council: Creating an Impact Through SDG 11
}

Keeley Bombard

Abigail Kahn

Ashley Pung

Matthew Folan

Rebecca Hyatt

See next page for additional authors

Follow this and additional works at: https://digitalcommons.mtu.edu/yeah-conference

\section{Recommended Citation}

Bombard, Keeley; Kahn, Abigail; Pung, Ashley; Folan, Matthew; Hyatt, Rebecca; and Zhang, Xingpei, "Session 2B Smart Cities Council: Creating an Impact Through SDG 11" (2020). Global Conference of the Youth Environmental Alliance in Higher Education. 31.

https://doi.org/10.37099/mtu.dc.yeah-conference/2020/all-events/31 


\section{Presenter Information}

Keeley Bombard, Abigail Kahn, Ashley Pung, Matthew Folan, Rebecca Hyatt, and Xingpei Zhang 


\section{Smart Cities Council: Creating an Impact using SDG 11}

Presentation by: Keeley Bombard and Rebecca Hyatt 


\section{What goal does SDG 11 address? Why is it important?}

- $\quad$ Rapid urbanization = pollution, inadequate housing, energy consumption, etc.

- "Make cities and human settlements inclusive, safe, resilient and sustainable"

- Relevant now: COVID-19

- $90 \%$ of COVID cases are in urban areas

- Right now, half of humanity (3.5 billion), by 2030, 5 billion

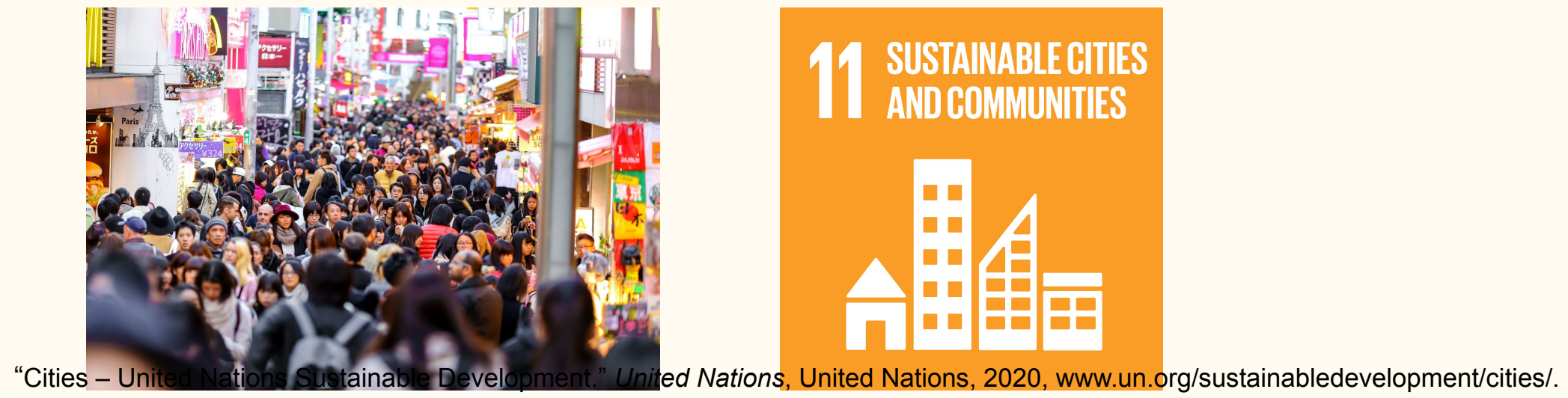

"Goal 11 | Department of Economic and Social Affairs." United Nations, United Nations, 2020, sdgs.un.org/goals/goal11. 
What are the specific objectives for the year 2030 related to your SDG?

- Ensure access for all to adequate, safe, and affordable housing and basic services.

- Provide a safe, affordable, accessible, and sustainable transport system for all.

- Enhance inclusive and sustainable urbanization and capacity for human settlement planning and management.

- Significantly reduce the number of deaths, people affected, and economic losses caused by disasters.

- Reduce the adverse per capita environmental impact of cities.

- Provide universal access to safe and accessible green and public spaces. 


\section{SmartCitiesCouncil \\ LIVABILITY | WORKABILITY | SUSTAINABILITY}

"Together, we seek to enhance the livability, workability and sustainability of the world's cities. We work to lower the barriers to adoption through actions that support and educate cities"
- Network of $40+$ companies, $75+$ expert advisors, 2 national laboratories, 11 universities

- Member companies employ: - Over 1 million, $150+$ countries

- 5,000 smart city projects globally

- How do they achieve their mission?

- Readiness Guide

- Financial tools

- Policy initiatives and advocacy

- Education and outreach 


\section{What is their specific objective related to SDG 11 ?}

- Act as an unbiased advisor to cities to optimize "livability, workability, and sustainability of cities through education and assistance."

- Provides resources to help cities improve quality of life and sustainably grow with assistance from businesses, labs, universities, and advisors.

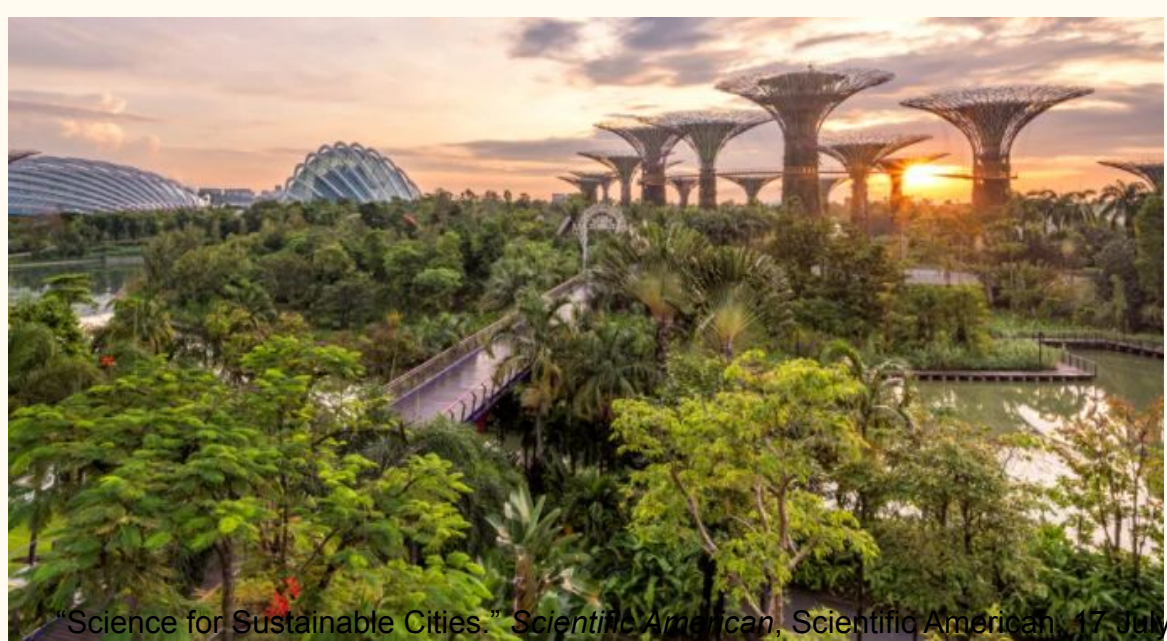

2018, www.scientificamerican.com/report/science-for-sustainable-cities1/. 


\section{What key strategies is the organization using to accomplish these objectives?}

\section{Smart Cities Council}

"Working globally to make cities more livable, workable and sustainable.

- Online platform for people to work together: Smart Cities Activator

- Experts that provide solutions to help cities

- Global Readiness Challenge to promote the progress of livability, workability, and sustainability of cities About Us, na.smartcitiescouncil.com/about-us-na Recent project: Nashville's March to Mitigate Urban Flooding Impact on Vulnerable Populations 


\section{How has the organization failed/succeeded?}

- Smart Cities Council been very successful in helping implement change in cities all over the globe

- Number of smart cities around the globe to increase to 88 by 2025 (currently at 21)

- Annual investments into smart cities to increase from $\$ 1$ billion to $\$ 12$ billion by 2025

- Room for improvement:

- Expansion of scope to South America, Africa, and The global smart city market is booming (US\$ billions)

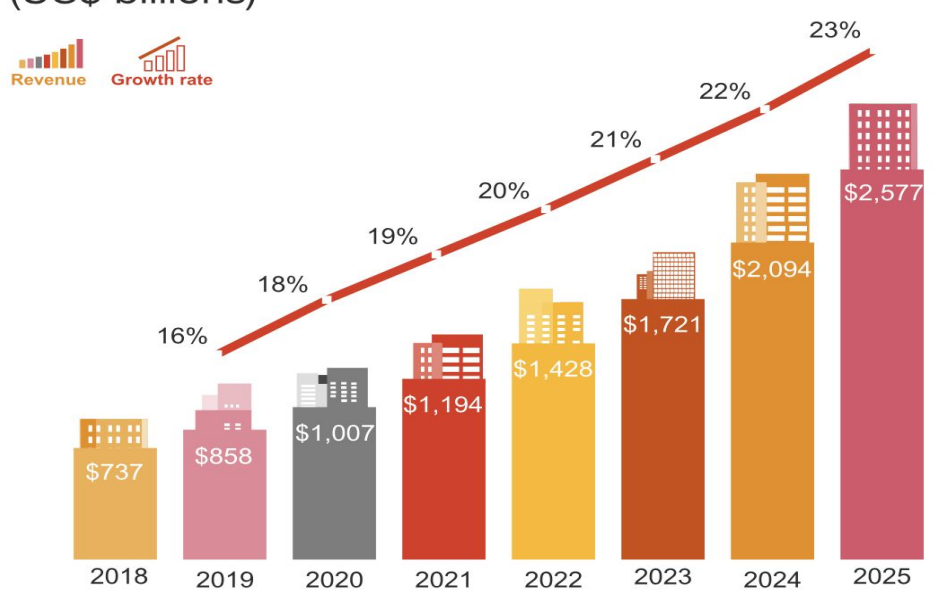
Asia

- Cities need to take initiative and apply to the 


\section{Thank you for listening!}

